Research Article

\title{
Genetic association of single nucleotide polymorphisms in dystrobrevin binding protein 1 gene with schizophrenia in a Malaysian population
}

\author{
Grace Kang Ning $\operatorname{Tan}^{1}$, Shiau Foon Tee $^{2}$ and Pek Yee Tang ${ }^{1}$ \\ ${ }^{1}$ Department of Mechatronics and Biomedical Engineering, Universiti Tunku Abdul Rahman, \\ Kuala Lumpur, Malaysia. \\ ${ }^{2}$ Department of Chemical Engineering, Universiti Tunku Abdul Rahman, Kuala Lumpur, Malaysia.
}

\begin{abstract}
Dystrobrevin binding protein 1 (DTNBP1) gene is pivotal in regulating the glutamatergic system. Genetic variants of the DTNBP1 affect cognition and thus may be particularly relevant to schizophrenia. We therefore evaluated the association of six single nucleotide polymorphisms (SNPs) with schizophrenia in a Malaysian population (171 cases; 171 controls). Associations between these six SNPs and schizophrenia were tested in two stages. Association signals with $p<0.05$ and minor allele frequency $>0.05$ in stage 1 were followed by genotyping the SNPs in a replication phase (stage 2). Genotyping was performed with sequenced specific primer (PCR-SSP) and restriction fragment length polymorphism (PCR-RFLP). In our sample, we found significant associations between rs2619522 (allele $p=0.002, O R=1.902,95 \% \mathrm{Cl}=1.266-2.859$; genotype $p=0.002$ ) and rs2619528 (allele $p=0.008, O R=1.606$, $95 \% \mathrm{Cl}=1.130-2.281$; genotype $\mathrm{p}=6.18 \times 10^{-5}$ ) and schizophrenia. Given that these two SNPs may be associated with the pathophysiology of schizophrenia, further studies on the other DTNBP1 variants are warranted.
\end{abstract}

Keywords: case-control study, DTNBP1, schizophrenia, single nucleotide polymorphism.

Received: May 7, 2014; Accepted: December 15, 2014.

\section{Introduction}

The dystrobrevin binding protein 1 (DTNBPl) gene, also known as dysbindin gene, is located at 6p22.3, a highly susceptible gene region of schizophrenia (Moises et al., 1995; Straub et al., 2002). It spans $140 \mathrm{~kb}$ along the chromosome and has 10 exons (Guo et al., 2009). It is one of the genes thought to be pivotal in regulating the glutamatergic system. In the human brain, DTNBP1 mRNA is predominantly expressed in the dorsolateral prefrontal cortex (DLPFC) and hippocampus (Weickert et al., 2004; Tang et al., 2009). Reduced DTNBP1 expression (Talbot et al., 2004; Weickert et al., 2004, 2008; Tang et al., 2009) was reported in schizophrenia patients. This reduction was inversely correlated with an increase of vesicular glutamate transporter 1 (VGluT-1) as a result of reduced lysosomal trafficking (Owen et al., 2004; Talbot et al., 2004). VGlut-1 served as the only vesicular glutamate transported in hippocampus (Kaneko et al., 2002). The increased V-Glut-1 could be a counter action of the reduced glutamate neurotransmitter. A low glutamate levels or a deficiency of the glutamate receptors will cause a diminished activation of the glutamate receptors. Individuals of lower glutamate re-

Send correspondence to Pek Yee Tang. Department of Mechatronics and Biomedical Engineering, Universiti Tunku Abdul Rahman, 53000 Kuala Lumpur, Malaysia. Email: tangpy@utar.edu.my. ceptor activation have showed schizophrenia like symptoms (Konradi and Heckers, 2003; Reynolds et al., 2005). Therefore, a lower expression of DTNBP1 may cause glutamate dysfunction and lead to the alteration of glutamatergic neurotransmission.

Dysbindin has been implicated in cognitive performance in healthy (Luciano et al., 2009) and schizophrenia cases (Burdick et al., 2006; Fallgatter et al., 2006). Genetic variants of DTNBP1 have been associated with working memory (Donohoe et al., 2007), IQ (Zinkstok et al., 2007; Fatjovilas et al., 2011) and execution function (Luciano et al., 2009; Fatjovilas et al., 2011). Along with the above findings, many case-control studies of DTNBP1 and schizophrenia have been performed. Positive associations have been observed in family studies (Straub et al., 2002; Tang et al., 2003), as well as in case-controls studies (Schwab et al., 2003; Voisey et al., 2010). Nevertheless, many other studies failed to replicate the previous positive associations (Morris et al., 2003; Li et al., 2005; Pae et al., 2009). A meta-analysis identified only weak association of one DTNBP1 SNP with schizophrenia, which was not significant after multiple testing ( $\mathrm{Li}$ and $\mathrm{He}, 2007)$. These discrepancies may indicate genetic heterogeneity of schizophrenia due to population differences. In Asia, case-control studies were conducted in Japan and Korea to investigate the association of DTNBP1 with schizophrenia (Numa- 
kawa et al., 2004; Joo et al., 2006; Tochigi et al., 2006; Pae et al., 2009). Two of the studied SNPs (rs2619522 and rs2619528) were associated in the Japanese population (Numakawa et al., 2004); however a replication of the two SNPs failed (Tochigi et al., 2006). On the contrary, studies in Korea (Joo et al., 2006; Pae et al., 2009) showed consistent results for rs2619522, in which no association of rs2619522 with the Korean schizophrenia patients was reported. Information on other Asian ethnics appear to be lacking.

Malaysia is a multiethnic country where the population is comprised of three major ethnic groups, Malays, Chinese and Indians. Ethnic distribution of total prevalence schizophrenia cases from 2003 to 2007 showed that Malays accounted for the highest percentage (53\%), followed by Chinese (30\%) and Indians (9\%) (Aziz et al., 2008). There have not been any published reports on the DTNBP1 polymorphisms in Malaysians. We thereby investigated the genetic association between DTNBP1 and schizophrenia in Malaysian subjects.

\section{Materials and Methods}

\section{Subjects}

The Malaysian sample consisted of 171 cases. The subjects were of mixed origin. Ethnicity and gender of the schizophrenia patients and control group are shown in Table 1. All schizophrenia cases are composed of in-patients recruited from the Hospital Bahagia Ulu Kinta (HBUK), Perak. The patients were hospitalized for more than three years. All of them met the Diagnostic and Statistical Manual of Mental Disorders-Fourth Edition (DSM-IV) diagnostic criteria. They were selected and interviewed by trained psychiatrists using the Mini International Neuropsychiatric Interview (MINI). MINI is a brief psychiatric structured diagnostic interview for Axis Diagnostic and Statistical Manual of Mental Disorders-Fourth Edition (DSM-IV) and International Classification of DiseasesTenth Edition (ICD 10) psychiatric disorders. MINI has been validated by senior psychiatrists and compared against Structured Clinical Interview for DSM-III-R (SCID) and Composite In-ternational Diagnostic Interview (CIDI) (Sheehan et al., 1998). Comorbidity of the patients was recorded during interview. Patients with comorbidity with other psychiatry disorders were excluded. The healthy controls were recruited from blood donation campaigns in various areas in Klang Valley. All controls were required to provide their medical history. The main inclusion criteria for controls were: free of any psychiatric illness, non drug abuser and without family history of psychiatric disorders. Written informed consent was obtained from all participants. This project was approved by the National Institutes of Health (NIH), Ministry of Health $(\mathrm{MOH})$ Malaysia (KKM/NIHSEC/08/0804/P07-42, NMRR-11189-8478).

\section{Genotyping}

Genotyping was performed in two stages. The subjects are comprised of 50 random patients and 50 controls in stage 1; stage 2 involved the addition of 121 patients and 121 controls on the existing participants in stage 1 . Increasing the total sample size in stage 2 was done in an attempt to reduce the false-positive associations from the results of stage 1 . Association signals with $\mathrm{p}<0.050$ and minor allele frequency $>0.050$ in stage 1 were followed-up by genotyping the SNPs in the replication phase (stage 2).

Genomic DNA was isolated from $20 \mathrm{cc}$ peripheral blood samples according to a standard phenol-chloroform method. Six single nucleotide polymorphisms (SNPs) were chosen in this study. Two genotyping approaches were used. Rs2619522, rs2619528 and rs1011313 were genotyped using the PCR-RFLP (restriction fragment length polymorphism) method (Buttner, 2009). Primer sequences are listed in Table 2 . The PCR products were digested with restriction enzymes (Table 2) and incubated at the specific optimum temperature (Table 2 ) for $3 \mathrm{~h}$. The digested products were analyzed on $3 \%$ agarose gel.

As there is no appropriate restriction site near the polymorphic sites of rs760761, rs3213207 and rs4236167, these three SNPs were genotyped using the PCR-SSP (sequence specific primer) method. Primer sequences (Table 2) were designed using Clone Manager Professional 9 (Scientific \& Educational Software, USA), with the polymorphic sites located at the 3' end of the primers. A primer pair was incorporated in each PCR reaction to ensure reliable amplification. The primer sequences for this positive control were 5'-TCGTGGACGCCGTGATTCAGG-3' and 5'AGGTCTGACAACGGGTCAGGCATG-3' (Nock et al., 2006). PCR products were resolved on $2 \%$ agarose gel. Three PCR products were randomly selected from each genotype for direct sequencing to validate the reliability of each genotyping method.

Table 1 - Demographic characteristics of the schizophrenia patients and controls.

\begin{tabular}{|c|c|c|c|c|c|c|c|c|}
\hline \multirow{2}{*}{$\begin{array}{l}\text { Gender } \\
\text { Ethnicity }\end{array}$} & \multicolumn{3}{|c|}{ Male } & \multirow[t]{2}{*}{ Total } & \multicolumn{3}{|c|}{ Female } & \multirow[t]{2}{*}{ Total } \\
\hline & Malay & Chinese & Indian & & Malay & Chinese & Indian & \\
\hline Patients & 32 & 36 & 19 & 87 & 26 & 42 & 16 & 84 \\
\hline Controls & 37 & 29 & 44 & 110 & 13 & 23 & 25 & 61 \\
\hline
\end{tabular}


Table 2 - The SNP primer sequences, detected alleles for PCR-SSP, restriction enzyme, and PCR product sizes.

\begin{tabular}{|c|c|c|c|c|c|}
\hline Genotyping method & SNP/Primer sequences 5'-3' & Detected Maj \& Min alleles & $\mathrm{RE}$ & PCR product size (bp) & $\mathrm{T}_{\mathrm{a}}\left({ }^{\circ} \mathrm{C}\right)$ \\
\hline \multirow[t]{5}{*}{ PCR-SSP } & rs760761 & & & 189 & 61.0 \\
\hline & F:GTGTCTAATTTTTATCTTGTTG & $\mathrm{G}$ & & & \\
\hline & R:GTACGGCTTCTTTATTAC & & & & \\
\hline & F:GTGTCTAATTTTTATCTTGTTA & (A) & & & \\
\hline & R:GTACGGCTTCTTTATTAC & & & & \\
\hline \multirow[t]{5}{*}{ PCR-SSP } & rs3213207 & & & 157 & 56.5 \\
\hline & F:CTTCCTTTCGTAAAGCCAA & A & & & \\
\hline & R:GTCACTTCTAAGTATACCCTG & & & & \\
\hline & F:CTTCCTTTCGTAAAGCCAG & (G) & & & \\
\hline & R:GTCACTTCTAAGTATACCCTG & & & & \\
\hline \multirow[t]{5}{*}{ PCR-SSP } & rs4236167 & & & 378 & 64.0 \\
\hline & F:GACCTTCTGGGCGTGCTCTG & & & & \\
\hline & R:CACTGGAGTTAGTAGAAGGACG & $\mathrm{C}$ & & & \\
\hline & F:GACCTTCTGGGCGTGCTCTG & & & & \\
\hline & R:CACTGGAGTTAGTAGAAGGACA & $(\mathrm{T})$ & & & \\
\hline \multirow[t]{3}{*}{ PCR-RFLP } & rs2619522 & & BseGI & & 55.8 \\
\hline & F:CTGTAACAGAGTCCACAG & $\mathrm{C}(\mathrm{A})$ & & 363 & \\
\hline & R:CCTGATACTTCTGACGTAG & & & & \\
\hline \multirow[t]{3}{*}{ PCR-RFLP } & rs2619528 & & HpyCHIV & 306 & 45.0 \\
\hline & F:GGAACTAAAATTGAATGT & G(A) & & & \\
\hline & R:GCACTTATATGATGTTCCTAG & & & & \\
\hline \multirow[t]{3}{*}{ PCR-RFLP } & rs1011313 & & HpyCHIV & 140 & 61.0 \\
\hline & F:CAGGCTACAGAATGGATGTTAC & $\mathrm{C}(\mathrm{T})$ & & & \\
\hline & R:GGCTGTATGAACAGAGTATCG & & & & \\
\hline
\end{tabular}

Maj-Major, Min-Minor. RE-Restriction enzyme. Ta-annealing temperature. Bold letters represent the 3' end nucleotides corresponding to the major and minor alleles.

\section{Statistical analysis}

Hardy-Weinberg Equilibrium (HWE) testing was performed using Arlequin version 3.11 (Excoffier et al., 2005). Allele and genotype frequencies were calculated and compared between patients and controls using a standard chi-square test (Statistical Package for the Social Science (SPSS) version 20, SPSS Inc., Chicago IL.). For subgroup analyses, patients were sub-divided according to subtypes of schizophrenia, gender and ethnicity. Residual and catatonic subtypes were not included due to limited case number (residual, $\mathrm{n}=10$, catatonic, $\mathrm{n}=1$ ). Three patients with unknown subtype were excluded for subgroup analysis according to schizophrenia subtype.

SNP data were converted into Haploview format using Microsoft-Excel (Chen et al., 2009). The linkage disequilibrium (LD) and haplotype map were obtained using Haploview version 4.2 (Broad Institute of MIT and Harvard, Cambridge) (Barrett et al., 2005).

\section{Results}

Allele and genotype frequencies of the respective SNPs in stage 1 are given in Table 3. Only two SNPs, rs1011313 (genotype $\mathrm{p}=0.047$ ) and rs2619528 (allele, $\mathrm{p}=0.038$; genotype, $\mathrm{p}=0.004$ ) showed significant association with schizophrenia among the six SNPs studied. Association analysis of rs2619522 showed a marginal allele difference between patients and controls $(p=0.060)$. Therefore, further screening was performed for rs 2619522 in addition with rs2619528 and rs 1011313 to eliminate the close proximity to a significant result.

In stage 2, genotype frequencies of both controls and patients were in HWE for rs1011313; whereas genotype frequencies in patients for rs2619528 and rs2619522 deviated from HWE (Table 4). The CC genotype of rs2619522 $(\mathrm{p}=0.002)$ and the $\mathrm{GG}$ genotype of $\mathrm{rs} 2619528(\mathrm{p}=6.18 \mathrm{x}$ $10^{-5}$ ) were significantly more abundant in patients, whereas positive association failed to be replicated for rs 1011313 .

The patients were further sub-classified into groups according to gender, ethnicity and subtypes. All these groups were compared with controls. Significant associations for rs2619522 and rs2619528 were observed in two subgroups, i.e. male patients and Malay patients. We detected interesting associations between DTNBP1 variants and subtypes of schizophrenia. Positive associations (allele $p=0.019$; genotype $p=0.036$ ) were only demonstrated be- 
Table 3 - Allele and genotype frequencies for the 6 SNPs of the DTNBP1 gene in stage 1 consisting of 50 patients and 50 controls.

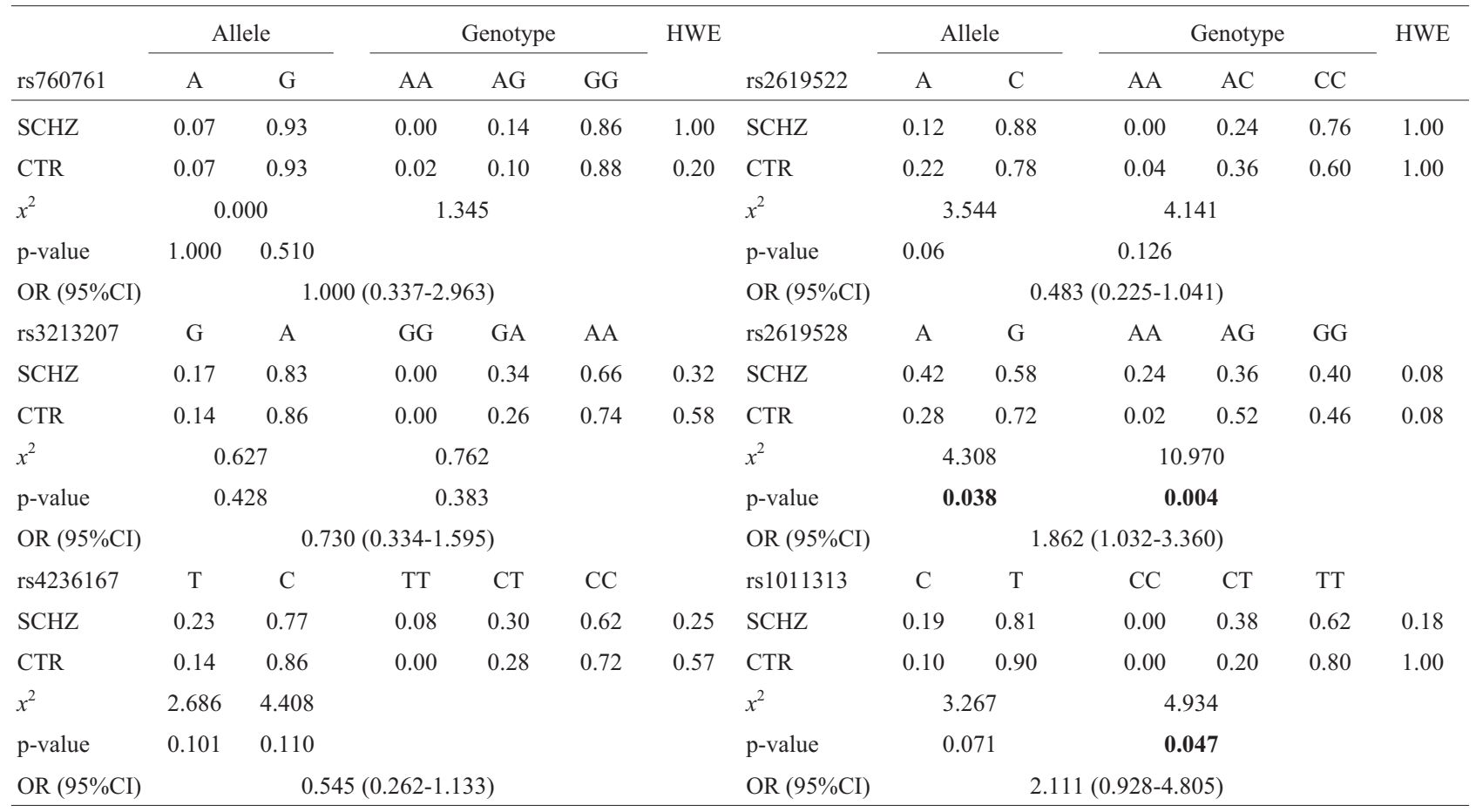

Significant p-values are shown in bold fonts. SCHZ-schizophrenia. CTR-control. HWE-Hardy-Weinberg Equilibrium.

tween rs2619522 and the patients of paranoid subtype, whereas significant associations between rs2619528 were shown in patients with the disorganized (allele $\mathrm{p}=0.004$; genotype $p=0.001$ ) and the undifferentiated (genotype $\mathrm{p}=0.013$ ) subtypes. None of the subtypes were associated with rs1011313 (Table 5).

Intermediate to strong linkage was observed between rs2619528 and rs2619522 (D' $=0.667$ and $\left.r^{2}=0.284\right)$ (Table 6). Two haplotypes, the G-C ( $\left.\mathrm{p}=6.0 \times 10^{-4}\right)$ and A-A $(p=0.021)$ haplotypes (Table 7$)$, were reported to be significantly associated with schizophrenia. The rare G-A haplotype was not investigated due to its low frequency $(<0.05)$. These two haplotypes were also found to be risk haplotypes in males, while the G-C haplotype $(\mathrm{p}=0.001)$ was significantly associated with schizophrenia in the Malays.

\section{Discussion}

After the stage 1 genotyping, three SNPs, rs760761, rs3213207 and rs4236167, were eliminated. Rs760761 is located in between rs2619522 and rs2619528 and strong linkage between rs2619522-rs760761-rs2619528 has been reported (Stefanis et al., 2007; Luciano et al., 2009; Pae et al., 2009). Although rs2619522 and rs2619528 were significant associated with schizophrenia in the Malaysians, rs760761 did not show any association. To date, the majority of case-control studies failed to show an association of rs3213207 with schizophrenia (Fallgatter et al., 2006; Sanders et al., 2008; Pae et al., 2009). The present results also concur with the meta-analysis performed by $\mathrm{Li}$ and $\mathrm{He}$
(2007), reporting that rs3213207 is not associated with schizophrenia. Rs4236167 was not widely studied so far. The negative association found in the current preliminary study is supported by Sanders et al. (2008) and Strohmaier et al. (2010). To date, only a weak association was reported with schizophrenia (Voisey et al., 2010). This indicates a low susceptibility of rs4236167 with schizophrenia.

A significant association of rs1011313 was observed in stage 1 genotyping, but the positive result could not be replicated in stage 2. Although rs1011313 was investigated in different populations (Funke et al., 2004; Pae et al., 2009; Strohmaier et al., 2010), most studies showed a negative association. Our observation further indicated that rs1011313 is unlikely to confer risk of schizophrenia.

For rs2619522, our results conferred strong associations with schizophrenia. Specifically, the CC variant of rs2619522 was associated with increased schizophrenia risk in the Malaysians. The positive results are in line with previous reports (Funke et al., 2004; Numakawa et al., 2004), where the $C$ allele conferred schizophrenia susceptibility. Moreover, association evidence of the $\mathrm{C}$ allele with lower memory and processing speed (Luciano et al., 2009) and intelligence were reported (Zhang et al., 2010). Due to a high rate $(80 \%)$ of neurocognitive impairment in Malaysian schizophrenia patients (Ibrahim et al., 2009), there is a possibility that schizophrenia patients with cognitive defects were included in this study. Our current study also revealed the significant association of rs2619522 in patients with the paranoid subtype. The result is supported by clini- 


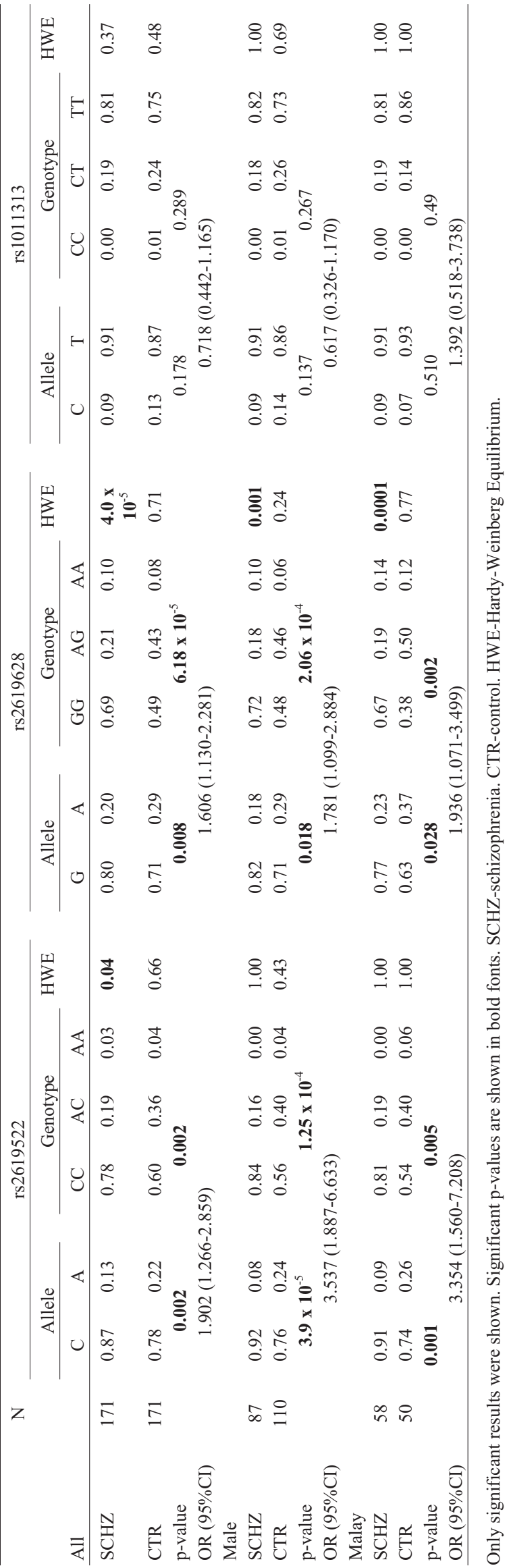

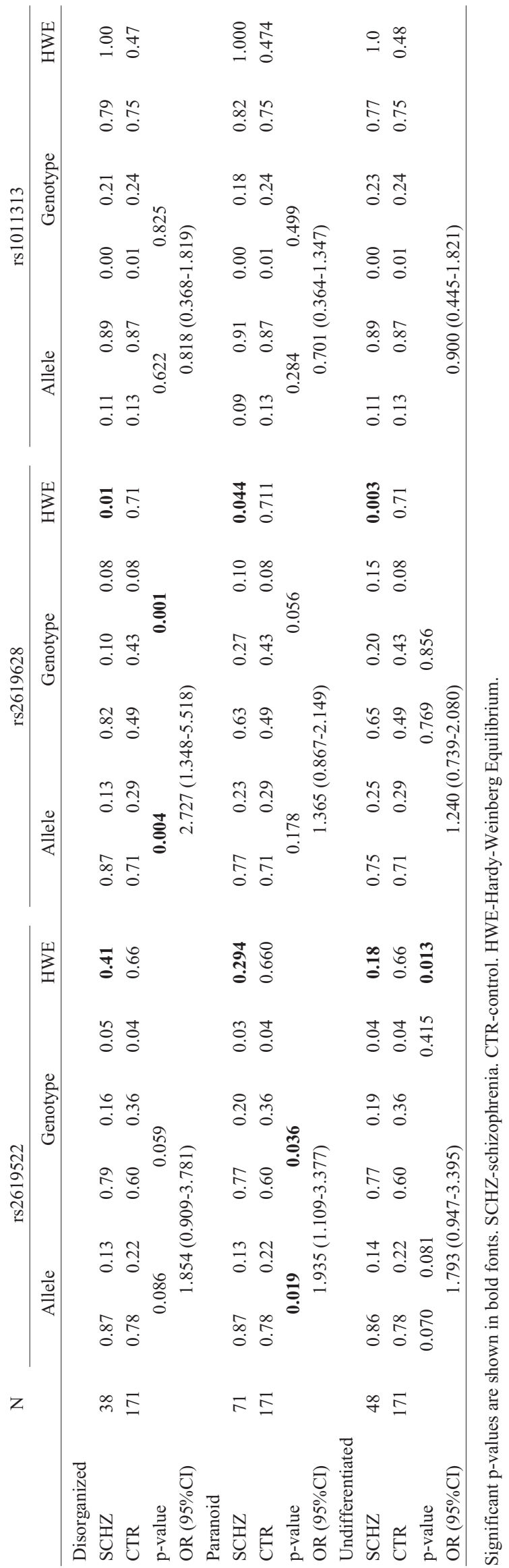


Table 6 - Pairwise linkage disequilibrium (LD) results.

\begin{tabular}{lccc}
\hline & rs1011313 & rs2618928 & rs2619522 \\
\hline rs1011313 & - & 0.128 & 0.052 \\
rs2618928 & 0.006 & - & 0.667 \\
rs2619522 & 0.002 & 0.284 & - \\
\hline
\end{tabular}

D' values are shown in the right upper diagonal. $\mathrm{r}^{2}$ values are shown in the left lower diagonal.

cal findings showing that the patients with the paranoid subtype had significantly worse results in memory, language, and execution functions compared to controls (Dillon et al., 2007).

For rs2619528, this is the first study in Asia that reported the $\mathrm{G}$ carriers showing higher risk of schizophrenia. The prefrontal cortex region connects and facilitates the implementation of cognition control and intelligence (Cole et al., 2012), and the GG genotype has been associated with prefrontal brain function disturbance (Fallgatter et al., 2010). Our study also showed significant association between the GG variant and schizophrenia in patients of disorganized and undifferentiated subtypes. This significant result may have been due to the cross-sectional relationships between the disorganized symptoms and cognitive deficits. A meta-analysis reported that disorganized symptoms were associated with majority cognitive domains, such as executive control, verbal fluency, attention, verbal learning and memory (Dominguez et al., 2009). The significant evidence in undifferentiated subtype patients was probably due to the partial disorganized symptoms observed in these patients. Patients with undifferentiated sub- type may display partial disorganized symptoms, but the intensity and duration of the disorganized symptoms may not be sufficient that they are classified as of the disorganized subtype (American Psychiatric Association, 1994). Notwithstanding, the findings might be biased due to the instability in the diagnosis of subtypes, where the patients of different subtypes have not been showing distinctive pattern of treatment responses or longitudinal courses.

We also observed a gender dimorphism, where the $\mathrm{C}$ allele (rs2619522) and G allele (rs2619528) increased the risk of schizophrenia in male patients. Up till date it is not yet clear, however, how rs2619528 and rs2619522 may increase the risk of schizophrenia in males. The association in male patients may probably be due to differences in brain structure for the two genders, as well as differences in neural lateralization (Antonova et al., 2004) that caused the male patients to exhibit deficits in clinical and cognitive domains (Han et al., 2012). Studies revealed that male patients showed more cognitive impairments than females (Seidman et al., 1997; Goldstein et al., 1998). As discussed, the DTNBP1 variants may be associated with cognitive ability (Zhang et al., 2010). We therefore infer that the male patients in this study could have been cognitively more impaired.

In addition to the above findings, our results showed positive associations of rs2679522 and rs2619528 with schizophrenia in Malays only. It is worthy of note that two significant SNPs, rs2619522 and -1438 G/A were associated with short term verbal memory in schizophrenia patients (Alfimova et al., 2010). Moreover, in a previous study, $-1438 \mathrm{G} / \mathrm{A}$ of the serotonin $2 \mathrm{~A}$ receptor gene (5-

Table 7 - Haplotype analysis for rs2619528-rs2619522.

\begin{tabular}{|c|c|c|c|c|c|}
\hline \multirow[t]{2}{*}{ rs2619528 - rs2619522 } & \multirow[t]{2}{*}{ Haplotype frequency } & \multicolumn{2}{|c|}{ Frequency } & \multirow[t]{2}{*}{$x^{2}$} & \multirow[t]{2}{*}{$\mathrm{p}$-value } \\
\hline & & Patient & Control & & \\
\hline \multicolumn{6}{|l|}{ All patients } \\
\hline G-C & 0.708 & 0.767 & 0.649 & 11.640 & $6.000 \times 10^{-4}$ \\
\hline A-A & 0.131 & 0.101 & 0.160 & 5.373 & 0.021 \\
\hline A-C & 0.118 & 0.104 & 0.132 & 1.289 & 0.256 \\
\hline G-A & 0.043 & 0.028 & 0.059 & - & - \\
\hline \multicolumn{6}{|l|}{ Male } \\
\hline G-C & 0.718 & 0.812 & 0.644 & 13.64 & $2.000 \times 10^{-4}$ \\
\hline A-A & 0.127 & 0.076 & 0.166 & 7.077 & 0.008 \\
\hline A-C & 0.114 & 0.107 & 0.120 & 0.155 & 0.694 \\
\hline G-A & 0.041 & 0.004 & 0.007 & - & - \\
\hline \multicolumn{6}{|l|}{ Malay } \\
\hline G-C & 0.664 & 0.760 & 0.552 & 10.45 & 0.001 \\
\hline A-A & 0.164 & 0.145 & 0.188 & 0.727 & 0.394 \\
\hline A-C & 0.132 & 0.089 & 0.182 & 4.156 & 0.042 \\
\hline G-A & 0.039 & 0.007 & 0.078 & - & - \\
\hline
\end{tabular}

Bold fonts represent significance at $\mathrm{p}<0.050 . x^{2}$ - chi square. 
HTR2A) was significantly associated with schizophrenia in the Malays (Tee et al., 2010). These evidences raise the possibility that the Malay patients in this study were cognitively more impaired than patients of other ethnic groups.

The strong linkage between rs2619528 and rs2619522 denoted in this study is well supported by previous reports (Numakawa et al., 2004; Li et al., 2005; Tochigi et al., 2006; Luciano et al., 2009). Our results indicate that the location of these two SNPs is likely to be a region for high schizophrenia susceptibility, as rs2619522 has been associated with schizophrenia (Funke et al., 2004; Numakawa et al., 2004). These two intronic SNPs could be in linkage disequilibrium with a functional SNP that has yet to be identified.

Based on the results of the Hardy-Weinberg Equilibrium test, the genotype distributions were in HWE for both patients and controls for rs 1011313. On the other hand, deviation of HWE was observed in patients for rs 2619528 and rs2619522. Frequently, deviation from HWE is an indication of possible errors in genotyping (Xu et al., 2002; Hosking et al., 2004), population stratification (Cardon and Palmer, 2003; Freedman et al., 2004) and biasness (Schaid and Jacobsen, 1999). In this study, however, there was no genotyping error, as our RFLP results were validated through sequencing. Population stratification is a form of confounding that arises when cases and controls are sampled from genetically distinct populations (Schork et al., 2001). Genotype distributions in our controls were in HWE, suggesting minimal stratification. Population stratification might exist in patients. Our patients, who had an average 8.67 years of hospitalization, were recruited from a small pool of inpatients in one hospital. Lastly, HWE testing is typically conducted in patients, and deviation in cases may indicate an association between the genotype and case-control status (Feder et al., 1996; Nielsen et al., 1999). Therefore, this may explain the deviation from HWE in patients for rs2619522 and rs2619528.

Limitations of this study are due to the relatively small sample size, and schizophrenia symptoms and cognitive ability that were not assessed during sample recruitment. A larger sample size would likely increase the statistical power of our results. Nonetheless, all patients were hospitalized for at least eight years. Their inpatient status minimizes discrepancy in diagnosis and clinical measures. Since schizophrenia is a multigenic disorder, further studies are needed to investigate the impact of other variants of $D T N B P 1$ and other genes.

\section{Acknowledgments}

This study was funded by the Fundamental Research Grant Scheme (FRGS/1/10/ST/UTAR/03/5 and RGS/2/2010/SKK/UTAR/03/4). The authors wish to thank the staffs of Hospital Bahagia Ulu Kinta (HBUK), Perak, for their referral of patients and blood sampling. The au- thors also wish to thank the staffs of National Blood Bank Malaysia for their kind assistance in recruiting healthy volunteers during blood donation campaigns.

\section{References}

Alfimova MV, Monakhov MV, Abramova LI, Golubev SA and Golimbet VE (2010) Polymorphism of serotonin receptor genes (5-HTR2A) and dysbindin (DTNBP1) and individual components of short-term verbal memory processes in schizophrenia. Neurosci Behav Physiol 40:934-940.

American Psychiatric Association (1994) Diagnostic and Statistical Manual of Mental Disorders. 4th edition. American Psychiatric Association, Washington DC, 886 pp.

Antonova E, Sharma T, Morris R and Kumari V (2004) The relationship between brain structure and neurocognition in schizophrenia: A selective review. Schizophr Res 70:117145.

Aziz AA, Salina AA, Abdul Kadir AB, Badiah Y., Cheah YC, Nor Hayati A, Ruzanna ZZ Sharifah Suziah SM and Chee KY (2008) The national mental health registry (NMHR). Med J Malaysia 63(Supp C):15-17.

Barrett JC, Fry B, Maller J and Daly MJ (2005) Haploview: Analysis and visualization of LD and haplotype maps. Bioinformatics 21:263-265.

Burdick KE, Lencz T, Funke B, Finn CT, Szeszko PR, Kane JM, Kuchierlapati R and Malhotra AK (2006) Genetic variation in DTNBP1 influences general cognitive ability. Hum Mol Genet 15:1563-1568.

Buttner S (2009) Dysbindin-1 (DTNBP-1) and Negative Symptoms in Patients with Schizophrenia. University Medicine Berlin, Berlin, 89 pp.

Cardon LR and Palmer LJ (2003) Population stratification and spurious allelic association. Lancet 361:598-604.

Chen B, Wilkening S, Drechsel M and Hemminki K (2009) SNP tools: A compact tool package for analysis and conversion of genotype data for MS-Excel. BMC Res Notes 2:e214.

Cole MW, Yarkoni T, Repovs G, Anticevic A and Braver TS (2012) Global connectivity of prefrontal cortex predicts cognitive control and intelligence. J Neurosci 32:8988-8999.

Dillon C, Taragano F, Sarasola D, Iturry M, Serrano C, Raczkowski A and Allegri R (2007) Cognitive performance in schizophrenia (paranoid vs residual subtype). Vertex 18:170-175.

Donohoe G, Morris D, Clarke S, Mcghee K, Schwaiger S, Nangle JM, Garavan H, Robertson IH, Gill M and Corvin A (2007) Variance in neurocognitive performance is associated with dysbindin-1 in schizophrenia: A preliminary study. Neuropsychologia 45:454-458.

Dominguez MG, Viechtbauer W and Simons JPC (2009) Are psychotic psychopathology and neurocognition orthogonal? A systematic review of their associations. Psychol Bull 135:157-171.

Excoffier L, Guillaume L and Schneider S (2005) Arlequin ver. 3.0: An integrated software package for population genetics data analysis. Evol Bioinform Online 1:47-50.

Fallgatter AJ, Herrmann MJ, Hohoff C, Ehlis AC, Jarczok TA, Freitag CM and Deckert J (2006) DTNBP1 (dysbindin) gene variants modulate prefrontal brain function in healthy individuals. Neuropsychopharmacology 31:2002-2010. 
Fallgatter AJ, Ehlis AC, Herrmann MJ, Hohoff C, Reif A, Freitag CM and Deckert J. (2010) DTNBP1 (dysbindin) gene variants modulate prefrontal brain function in schizophrenic patients-support for the glutamate hypothesis of schizophrenias. Genes Brain Behav 9:489-97.

Fatjovilas M, Papiol S, Estrada G, Bombin I, Peralta V, Rosa A, Parellada M, Miret S, Martin M, Lazaro L et al. (2011) Dysbindin-1 gene contributes differentially to early- and adult onset forms of functional psychosis. Am J Med Genet Part B 156:322-333.

Feder JN, Gnirke A, Thomas W, Tsuchihashi Z, Ruddy DA, Basava A, Dormishian F, Domingo Jr R, Ellis MC, Fullan A et al. (1996) A novel MHC class I-like gene is mutated in patients with herrditary haemochromatosis. Nat Genet 13:399-408.

Freedman ML, Reich D, Penney KL, McDonald GJ, Mignault AA, Patterson N, Gabriel SB, Topol EJ, Smoller JW, Pato $\mathrm{CN}$ et al. (2004) Assessing the impact of population stratification on genetic association studies. Nat Genet 36:388-393.

Funke B, Finn CT, Plocik AM, Lake S, Derosse P, Kane JM, Kucherlapati R and Malhotra AK (2004) Association of the DTNBP1 locus with schizophrenia in a U.S. population. Am J Hum Genet 75:891-898.

Goldstein JM, Seidman LJ, Goodman JM, Koren D, Lee H, Weintraub S and Tsuang MT (1998) Are there sex differences in neuropsychological functions among patients with schizophrenia? Am J Psychiatry 155:1358-1364.

Guo AY, Sun J, Riley BP, Thiselton DL, Kendler KS and Zhao Z (2009) The dystrobrevin-binding protein 1 gene: Features and networks. Mol Psychiatry 14:18-29.

Han M, Huang XF, Chen DC, Xiu MH, Hui L, Liu H, Kosten TR and Zhang XY (2012) Gender differences in cognitive function of patients with chronic schizophrenia. Prog Neuropsychopharmacol Biol Psychiatry 39:358-363.

Hosking L, Lumsden S, Lewis K, Yeo A, McCarthy L, Bansal A, Riley J, Purvis I and Xu CF (2004) Detection of genotyping errors by Hardy-Weinberg equilibrium testing. Eur J Hum Genet 12:395-399.

Ibrahim N, Abdul RAH and Shah A (2009) Neuro-cognitive performance in patients with schizophrenia: A cross-sectional study in psychiatric clinic of a University Hospital. Malays J Med Health Sci 5:21-30.

Joo EJ, Lee KY, Jeong SH, Ahn YM, KooYJ and Kim YS (2006) The dysbindin gene (DTNBP1) and schizophrenia: No support for an association in the Korean population. Neurosci Lett 407:101-106.

Kaneko T, Fujiyama F and Hioki H (2002) Immunohistochemical localization of candidates for vesicular glutamate transporters in the rat brain. J Comp Neurol 444:39-62.

Konradi C and Heckers S (2003) Molecular aspects of glutamate dysregulation: Implications for schizophrenia and its treatment. Pharmacol Ther 97:153-179.

Li D and He L (2007) Meta-analysis supports association between serotonin transporter (5-HTT) and suicidal behavior. Mol Psychiatry 12:47-54.

Li T, Zhang F, Liu X, Sun X, Sham PC, Crombie C, Ma X, Wang Q, Meng H, Deng W et al. (2005) Identifying potential risk haplotypes for schizophrenia at the DTNBP1 locus in Han Chinese and Scottish populations. Mol Psychiatry 10:10371044.
Luciano M, Miyajima F, Lind PA, Bates TC, Horan M, Harris SE, Wright MJ, Ollier WE, Hayward C, Pendleton $\mathrm{N}$ et al. (2009) Variation in the dysbindin gene and normal cognitive function in three independent population samples. Genes Brain Behav 8:218-227.

Moises HW, Yang L, Kristbjarnarson H, Wiese C, Byerley W, Macciardi F, Arolt V, Blackwood D, Liu X, Sjogren B et al. (1995) An international two-stage genome-wide search for schizophrenia susceptibility genes. Nat Genet 11:321-324.

Morris DW, Mcghee KA, Schwaiger S, Scully P, Quinn J, Meagher D, Waddington JL, Gill M and Corvin AP (2003) No evidence for association of the dysbindin gene [DTNBP1] with schizophrenia in an Irish population-based study. Schizophr Res 60:167-172.

Nielsen DM, Ehm MG and Weir BS (1999) Detecting markerdisease association by testing for Hardy-Weinberg disequilibrium at marker locus. Am J Hum Genet 63:1531-1540.

Nock NL, Cicek MS, Li L, Liu X, Rybicki BA, Moreira A, Plummer SJ, Casey G and Witte JS (2006) Polymorphisms in estrogen bioactivation, detoxification and oxidative DNA base excision repair genes and prostate cancer risk. Carcinogenesis 27:1842-1848.

Numakawa T, Yagasaki Y, Ishimoto T, Okada T, Suzuki T, Iwata $\mathrm{N}$, Ozaki N, Taguchi T, Tatsumi M, Kamijima K et al. (2004) Evidence of novel neuronal functions of dysbindin, a susceptibility gene for schizophrenia. Hum Mol Genet 13:2699-2708.

Owen MJ, Williams NM and Donovan MC (2004) Dysbindin-1 and schizophrenia: From genetics to neuropathology. J Clin Invest 113:1255-1257.

Pae CU, Mandelli L, De Ronchi D, Kim JJ, Jun TY, Patkar AA and Serretti A (2009) Dysbindin gene (DTNBP1) and schizophrenia in Korean population. Eur Arch Psychiatry Clin Neurosci 259:137-142.

Reynolds LM, Cochran SM, Morris BJ, Pratt JA and Reynolds GP (2005) Chronic phencyclidine administration induces schizophrenia-like changes in $\mathrm{N}$-acetylaspartate and $\mathrm{N}$ acetylaspartylglutamate in rat brain. Schizophr Res 73:147152.

Sanders AR, Duan J, Levinson DF, Shi J, He D, Hou C, Burrell GJ, Rice JP, Nertney DA, Olincy A et al. (2008) No significant association of 14 candidate genes with schizophrenia in a large European ancestry sample: Implications for psychiatric genetics. Am J Psychiatry 165:497-506.

Schaid DJ and Jacobsen SJ (1999) Biased tests of association: Comparison of allele frequencies when departing from Hardy-Weinberg proportions. Am J Epidemiol 149:706711.

Schork NJ, Fallin D, Thiel B, Xu X, Broeckel U, Jacob HJ and Cohen $\mathrm{D}$ (2001) The future of genetic case-control studies. Adv Genet 42:191-212.

Schwab SG, Knapp M, Mondabon S, Hallmayer J, BorrmannHassenbach M, Albus M, Lerer B, Rietschel M, Trixler M, Maier W et al. (2003) Support for association of schizophrenia with genetic variation in the $6 \mathrm{p} 22.3$ gene, dysbindin, in sib-pair families with linkage and in an additional sample of triad families. Am J Hum Genet 72:185-190.

Seidman LJ, Goldstein JM, Goodman JM, Koren D, Turner WM, Faraone SV and Tsuang MT (1997) Sex differences in olfactory identification and Wisconsin Card Sorting performance 
in schizophrenia: Relationship to attention and verbal ability. Biol Psychiatry 42:104 -115.

Sheehan DV, Lecrubier Y, Sheehan KH, Amorim P, Janavs J, Weiller E, Hergueta T, Baker R and Dunbar GC (1998) The Mini-International Neuropsychiatric Interview (M.I.N.I.): The development and validation of a structured diagnostic psychiatric interview for DSM-IV and ICD-10. J Clin Psychiatry 59(Suppl 20):22-33.

Stefanis NC, Trikalinos TA, Avramopoulos D, Smyrnis N, Evdokimidis L, Ntzani EE, Ioannidis JP and Stefanis CN (2007) Impact of schizophrenia candidate genes on schizotypy and cognitive endophenotypes at the population level. Biol Psychiatry 62:784-792.

Straub RE, Maclean CJ, Ma Y, Webb BT, Myakishev MV, Harris-Kerr C, Wormley B, Sadek H, Kadambi B, O'Neill FA et al. (2002) Genome-wide scans of three independent sets of 90 Irish multiplex schizophrenia families and follow-up of selected regions in all families provides evidence for multiple susceptibility genes. Mol Psychiatry 7:542-559.

Strohmaier J, Frank J, Wendland JR, Schumacher J, Jamra RA, Treutlein J, Nieratschker V, Breuer R, Mattheisen M, Herms $\mathrm{S}$ et al. (2010) A reappraisal of the association between dysbindin (DTNBP1) and schizophrenia in a large combined case-control and family-based sample of German ancestry. Schizophr Res 118:98-105.

Talbot K, Eidem WL, Tinsley CL, Benson MA, Thompson EW, Smith RJ, Hahn CG, Siegel SJ, Trojanowski JQ, Gur RE et al. (2004) Dysbindin-1 is reduced in intrinsic, glutamatergic terminals of the hippocampal formation in schizophrenia. $\mathrm{J}$ Clin Invest 113:1353-1363.

Tang JX, Zhou J, Fan JB, Li XW, Shi YY, Gu NF, Feng GY, Xing YL, Shi JG and He L (2003) Family-based association study of DTNBP1 in 6p22.3 and schizophrenia. Mol Psychiatry 8:717-718.

Tang J, Legros RP, Louneva N, Yeh L, Cohen JW, Hahn CG, Blake DJ, Arnold SE and Talbot K (2009) Dysbindin-1 in dorsolateral prefrontal cortex of schizophrenia cases is reduced in an isoform-specific manner unrelated to dysbindin-1 mRNA expression. Hum Mol Genet 18:3851-3863.
Tee SF, Chow TJ, Tang PY and Loh HC (2010) Linkage of schizophrenia with TPH2 and 5-HTR2A gene polymorphisms in the Malay population. Genet Mol Res 9:12741278.

Tochigi M, Zhang X, Ohashi J, Hibino H, Otowa T, Rogers M, Kato T, Okazaki Y, Kato N, Tokunaga K et al. (2006) Association study of the dysbindin (DTNBP1) gene in schizophrenia from the Japanese population. Neurosci Res 56:154-158.

Voisey J, Swagell CD, Hughes IP, Lawford BR, Young RM and Morris CP (2010) Analysis of HapMap tag-SNPs in dysbindin (DTNBP1) reveals evidence of consistent association with schizophrenia. Eur Psychiatry 25:314-319.

Weickert CS, Straub RE, McClintock BW, Matsumoto M, Hashimoto R, Hyde TM, Herman MM, Weinberger DR and Kleinman JE (2004) Human dysbindin (DTNBP1) gene expression in normal brain and in schizophrenic prefrontal cortex and midbrain. Arch Gen Psychiatry 61:544-555.

Weickert CS, Rothmond DA, Hyde TM, Kleinman JE and Straub RE (2008) Reduced DTNBP1 (dysbindin-1) mRNA in the hippocampal formation of schizophrenia patients. Schizophr Res 98:105-110.

Xu J, Turner A, Little J, Bleeker ER and Meyers DA (2002) Positive results in association studies are associated with departure from Hardy-Weinberg equilibrium: Hint for genotyping error? Hum Genet 111:573-574.

Zinkstok JR, De Wilde O, Van Amelsvoort TA, Tanck MW, Baas F and Linszen DH (2007) Association between the DTNBP1 gene and intelligence: a case-control study in young patients with schizophrenia and related disorders and unaffected siblings. Behav Brain Funct 3:1-10.

Zhang JP, Burdick KE, Lencz T and Malhotra AK (2010) Metaanalysis of genetic variation in DTNBP1 and general cognitive ability. Biol Psychiatry 68:1126-1133.

Associate Editor: Patrícia Ashton Prolla

License information: This is an open-access article distributed under the terms of the Creative Commons Attribution License, which permits unrestricted use, distribution, and reproduction in any medium, provided the original work is properly cited. 